\title{
Recent progress in the asymmetric Mannich reaction
}

\author{
Cai Xiao-Huaa,*, Guo Huib and Xie Binga \\ a College of Chemistry and Environmental Science, Guizhou Minzu University, Guiyang, 550025, China \\ b College of Pharmaceutical Sciences, Zhejiang University of Technology, Hangzhou, 310014, China \\ ${ }^{*}$ Corresponding author at: College of Chemistry and Environmental Science, Guizhou Minzu University, Guiyang, 550025, China \\ Tel.: +86.851.3610313; fax: +86.851.3610313. E-mail address: caixh1111@163.com (C. Xiao-Hua).
}

\section{REVIEW INFORMATION}

\section{Received: 02 October 2011}

Received in revised form: 09 January 2012

Accepted: 09 January 2009

Online: 30 June 2012

\section{KEYWORDS}

Chiral amine catalysis

Chiral Bronsted acid

Asymmetric organocatalysis

Metal-based organocatalysis

Asymmetric Mannich reaction

Diastereo- and enantioselective

\section{Introduction}

Recently, the development of asymmetric Mannich reactions has attracted considerable attention [1-3]. The asymmetric Mannich reaction is one of the most powerful carbon-carbon bond-forming reactions for the construction of nitrogen-containing compounds [4-6]. The utilization of this reaction allows for the preparation of optically enriched $\beta$ amino carbonyl compounds and their derivatives. In some instances these reactions have proven effective for the generation of biologically significant and synthetically useful $\beta$ amino acids that contain a quaternary stereocenter substituted with a nitrogen atom adjacent to the carbonyl group [7-9]. Traditionally, asymmetric Mannich reactions are catalyzed by chiral transition-metal complexes. In recent years, organocatalysed versions of asymmetric Mannich processes have been increasingly reported and used in a rapidly growing number of applications. This review will provide an overview of the recent history of the applications of different catalytic systems in asymmetric Mannich reactions, including metalbased organocatalysis, asymmetric organocatalysis, other chiral catalysis and no chiral catalysis systems.

\section{Metal-based organocatalytic systems}

Metal-based chiral organocatalytic systems in asymmetric Mannich reactions can be divided into two:

i) chiral transition-metal complexes organocatalyst and,

ii) chiral organocatalysts and metal salts.

\subsection{Chiral transition-metal complexes}

The dinuclear nickel metal catalysis is an important catalysis for the direct catalytic asymmetric Mannich-type reactions in high yield as well as stereoselectivity. In 2008, Matsunaga and Shibasaki [10] reported the direct catalytic asymmetric Mannich-type reactions of $\beta$-keto phosphonates with aryl and heteroaryl $\mathrm{N}-\mathrm{Boc}$ imines promoted by a homodinuclear $\mathrm{Ni}_{2}$-Schiff base complex (1) (Scheme 1). The reaction proceeded $\beta$-amino phosphonates were obtained in $43-90 \%$ yield, $20: 1-2: 1 \mathrm{dr}$, and $47-99 \%$ ee. Two years later, they developed the direct catalytic asymmetric vinylogous Mannich-type and Michael reactions of $\alpha, \beta$-unsaturated $\gamma$ butyrolactam and $N$-Boc imines under dinuclear nickel catalysis [11]. The dinuclear Ni-catalyzed reactions proceeded selectively at the $\gamma$-position, giving vinylogous Mannich adducts in 5:1-30:1 dr and 99\% ee (Scheme 2) and vinylogous Michael adducts in 16:1-30:1 dr and 93-99\% ee (Scheme 3).

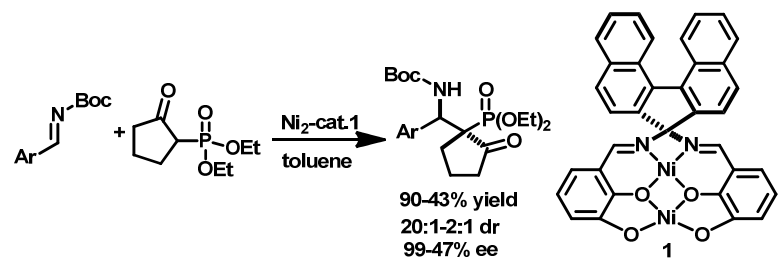

Scheme 1

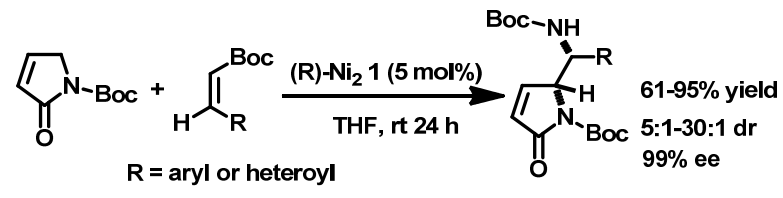

Scheme 2

Liu Hong and co-workers [12] described a practical and highly efficient enantio- and diastereoselective route to syn- 
configured $\alpha, \beta$-diamino acids between a chiral Ni(II) complex of glycine and $\alpha$-amino sulfones, involving the creation of a carbon-carbon bond and two stereogenic centers in a single operation (Scheme 4), representing an attractive route to the synthesis $\alpha, \beta$-diamino acids.

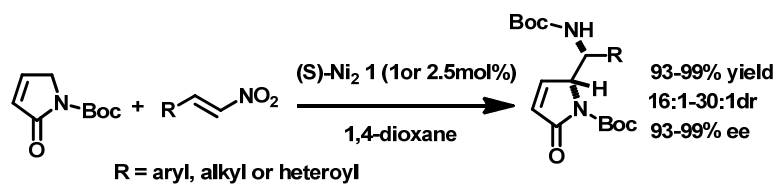

Scheme 3

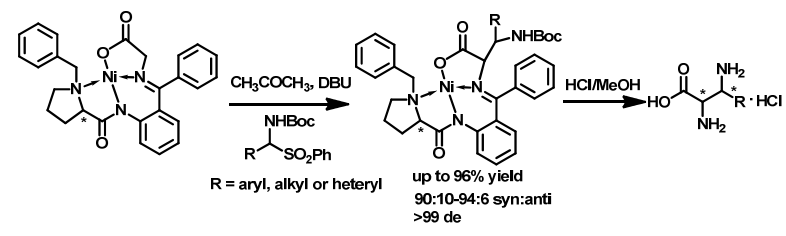

Scheme 4

In 2011, Kang and Kim [13] developed the highly efficient catalytic enantioselective Mannich reaction of $\alpha$-fluoro- $\beta$ ketoesters catalysed by chiral palladium complexes (2) which are air- and moisture- stable. The desired $\beta$-aminated products were obtained in good to high yields, and high enantioselectivities (up to $99 \%$ ee) were observed for all the substrates examined in this work. This method provided a practical entry for the preparation of chiral $\beta$-aminated $\alpha$ fluoro- $\beta$-ketoesters derivatives (Scheme 5 and 6).

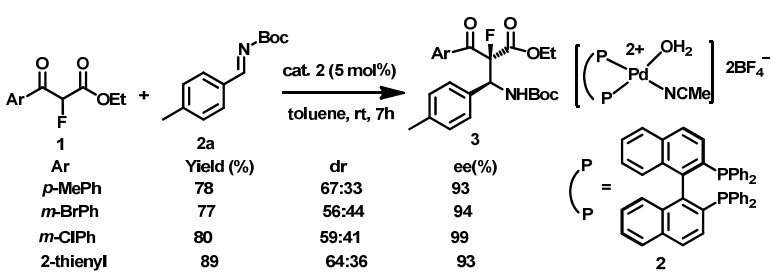

Scheme 5

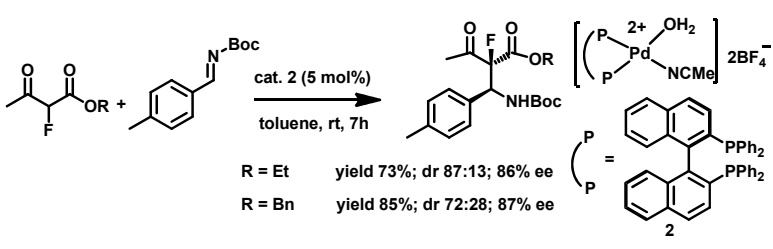

Scheme 6

Matsunaga and Shibasaki [14] described the full details of a catalytic asymmetric syn-selective nitro-Mannich reaction promoted by heterobimetallic $\mathrm{Cu} / \mathrm{Sm} /$ dinucleating Schiff base complexes, and demonstrated the effectiveness of the heterobimetallic transition metal/rare earth metal bifunctional catalysis (3) (Scheme 7). The first-generation system prepared from $\mathrm{Cu}(\mathrm{OAc})_{2} / \mathrm{Sm}(\mathrm{O} \text {-iPr })_{3} / \mathrm{Schiff}$ base 1:1:1 with an achiral phenol additive was partially successful for achieving the synselective catalytic asymmetric nitro-Mannich reaction. The substrate scope and limitations of the first-generation system remained problematic. After mechanistic studies on the catalyst prepared from $\mathrm{Sm}(\mathrm{O}-\mathrm{iPr})_{3}$, they reoptimized the catalyst preparation method, and a catalyst derived from $\mathrm{Sm}_{5} \mathrm{O}(0-\mathrm{iPr})_{13}$ showed broader substrate generality as well as higher reactivity and stereoselectivity compared to $\mathrm{Sm}(\mathrm{O}-\mathrm{iPr})_{3}$. The optimal system with $\mathrm{Sm}_{5} \mathrm{O}(\mathrm{O} \text {-iPr })_{13}$ was applicable to various aromatic, heteroaromatic, and isomerizable aliphatic $N$-Boc imines, giving products in 66-99\% ee and syn/anti > 20:1-13:1.

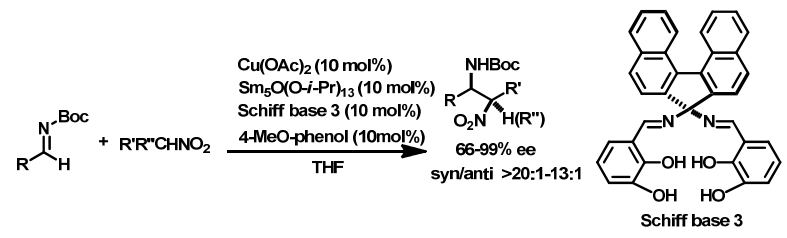

Scheme 7

\subsection{Chiral organocatalysts and metal salts}

In 2010, Feng [15] developed the highly enantioselective three-component vinylogous Mannich reaction of aldehydes, 2aminophenol and using a chiral $N, N^{\prime}$-dioxide-scandium (III) complex (4) as the catalyst (Scheme 8). A variety of aldehydes were found to be suitable substrates for the reaction and the desired $\delta$-amino- $\alpha, \beta$-unsaturated esters were obtained in 90 $99 \%$ yields with good to excellent enantioselectivities (up to $>99 \%$ ee) and complete regioselectivities. Nonactivated natural $\alpha$-angelica lactone was demonstrated to be a useful vinylogous nucleophile to afford the chiral $\delta$-amino $\gamma, \gamma$-disubstituted butenolide carbonyl derivatives. Later, Feng [16] reported a direct highly diastereo- and enantioselective asymmetric vinylogous Mannich-type (AVM) reaction of aldimines with $\alpha$ angelica lactone using $N, N^{\prime}$-dioxide (5) -Sc(OTf) $)_{3}$ complex as catalyst affording a range of the corresponding products with adjacent quaternary and tertiary stereocenters in good diastereo- and enantioselectivities (Scheme 9).

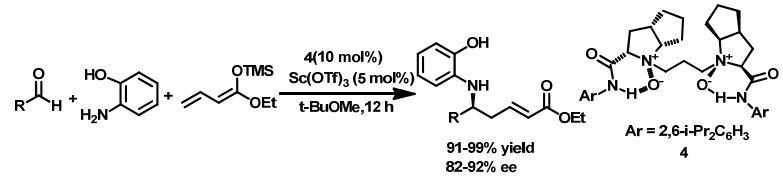

Scheme 8

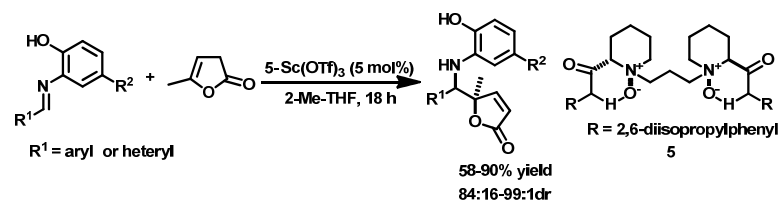

Scheme 9

Shi et al. [17] found that axially chiral phosphine-oxazoline ligand (6), prepared from (S)-binol, was a fairly effective chiral ligand in the silver(I)-catalyzed asymmetric Mannich reaction of fluorinated aldimines with trimethylsiloxyfuran (Scheme 10). They reported the first example of silver(I)-catalyzed catalytic asymmetric Mannich reaction of fluorinated imines with trimethylsiloxyfuran in the presence of chiral phosphineoxazoline ligand 6 in THF under mild conditions, affording the corresponding adducts in up to $99 \%$ yield, over 20:1 dr and $81 \%$ ee. In subsequent publication, Shi [18] reported a silver(I)-catalyzed catalytic asymmetric Mannich reaction of $N$ Boc imines with trimethylsiloxyfuran in the presence of chiral phosphineoxazoline ligand $\mathbf{6}$ in $\mathrm{CH}_{2} \mathrm{Cl}_{2}$ under mild conditions, affording the corresponding adducts in up to $97 \%$ yield, 7:1 dr and $86 \%$ ee (major diastereoisomer) (Scheme 11).

Curti et al. [19] described the catalytic, asymmetric vinylogous Mukaiyama Mannich reactions of pyrrole-based silyl dienolates with a series of $\mathrm{N}$-arylimines in the presence of the Hoveyda-Snapper amino acid (7) derived silver(I) catalysts 
(Scheme 12). The Mannich products $\alpha, \beta$-unsaturated $\delta$-amino$\gamma$-butyrolactams are typically obtained in high yields, excellent $\gamma$-site selectivities and anti-diastereoselectivities, and up to $80 \%$ enantioselectivity.

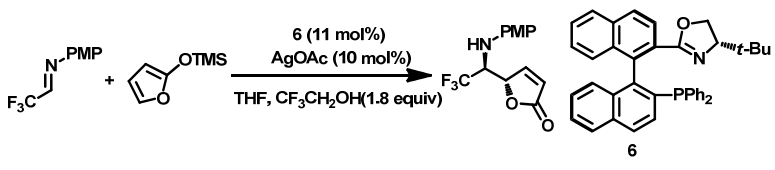

Scheme 10

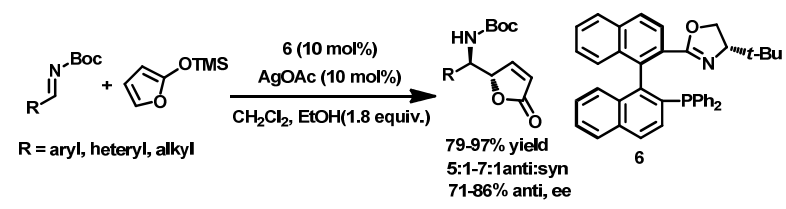

Scheme 11

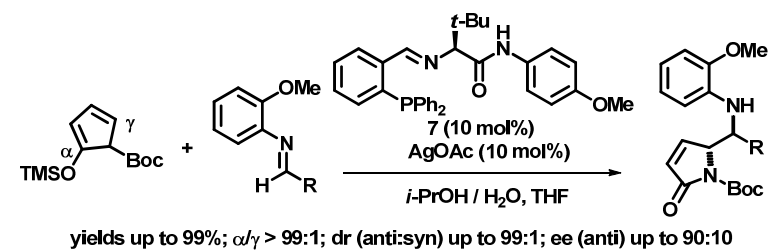

Scheme 12

In 2010, Kobayashi and co-worhers [20] introduced the use of the chiral Ca-Py Box complex in the Mannich reaction of malonates with $\mathrm{N}$-Boc imines (Scheme 13). The corresponding adducts were obtained within $2 \mathrm{~h}$ in high yields (up to 95\%) with good to moderate enantioselectivitiy (up to $77 \%$ ee).

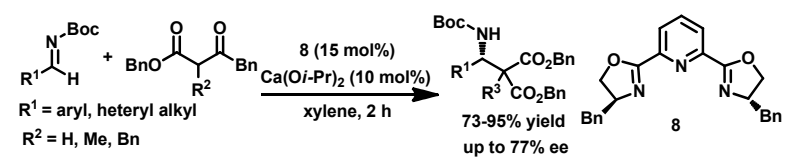

Scheme 13

Wang et al. [21] developed a highly anti-selective Mannich reaction of glycine Schiff bases with $N$-tosylimines (Scheme 14). The efficient $\left[\mathrm{Cu}\left(\mathrm{CH}_{3} \mathrm{CN}\right)_{4} \mathrm{BF}_{4}\right] / \mathrm{TF}$ - biphamphos (9) catalytic system exhibited excellent performance, affording anti-adducts of various $\alpha, \beta$-diamino acid esters with up to $94: 6$ diastereoselectivity and $97 \%$ enantioselectivity.

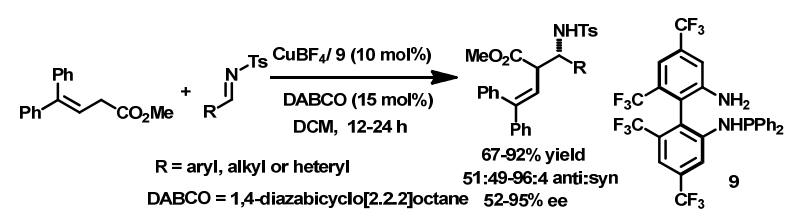

Scheme 14

Arrayás et al. [22] disclosed the diastereoselectivity switch from anti- to syn- in the catalytic asymmetric direct Mannich reaction of glycine derivatives with $\mathrm{N}$-(8-quinolyl)-sulfonyl imines by tuning the steric and electronic properties of the glycine imine (Scheme 15). $\alpha, \beta$-Diamino acids of synconfiguration were produced with glycinate esters derived from electron-deficient benzophenone-type ketimines, in contrast to aldimine-derived pronucleophiles that led to anti- configured products. The Fesulphos-CuI catalyst is crucial for achieving high asymmetric induction.

\section{Organocatalytic systems}

By the end of the last century numerous successful examples of asymmetric organocatalytic reactions had been developed as a viable approach for producing enantiomerically pure compounds. Thus, the area of enantioselective organocatalysis became a main focus of research. In 2000 List described firstly the L-proline catalysed Mannich reaction [2325], this landmark discovery stimulated the rapid development of the asymmetric organocatalytic Mannich reactions.

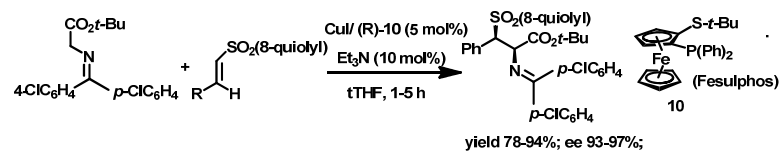

Scheme 15

\subsection{Chiral amines}

Chiral amines have the possibility to react with so-called Mannich donors such as ketones or aldehydes. The resulting chiral enamines can attack a Mannich acceptor, usually a prochiral aldimine, thereby introducing one or two chiral centers in the Mannich product. The catalytic cycle is completed by regeneration of the amine catalyst through hydrolysis. The products are $\beta$-aminoaldehydes or $\beta$ aminoketones, which are optionally substituted at the $\alpha$ position [5].

\subsubsection{L-Proline and its derivatives}

Among a wide variety of organocatalysts that have been used in the asymmetric Mannich reaction, the most widely used is proline. In 2008, Xu and coworkers [26] reported an enantioselective synthetic method for substituted tetrahydropyridines via a proline-mediated cascade Mannichtype/intramolecular cyclization (Scheme 16). A noteworthy advantage of the method was the NPMP aldimines from inexpensive aqueous materials tetrahydro- $2 \mathrm{H}$-pyran-2,6-diol were easily prepared with excellent diastereo- and enantioselectivity in the presence of water. In the same year, Glorius et al. [27] developed the highly enantio- and antiselective proline-catalyzed Mannich reaction of unactivated ketones, and demonstrated that the use of cyclic acceptors enables the highly stereoselective synthesis of chiral 3substituted 1,4-morpholin-2-ones (Scheme 17). These products correspond to $\alpha$-D-amino acids that were protected at the $\mathrm{N}$ and $\mathrm{O}$ terminus by the diphenylethylene group. This protecting group for $\alpha$-amino acids could be cleaved readily by hydrogenolysis in aqueous ethanol to furnish the free amino acid.

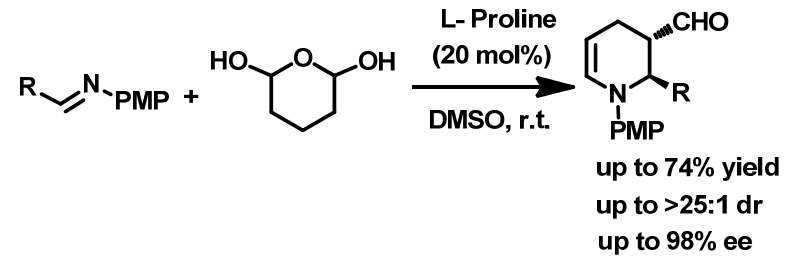

Scheme 16

List [25] introduced an efficient method for the one-pot catalytic asymmetric synthesis of pseudo- $C_{2}$-symmetric $\beta, \beta^{\prime}$ diaminoaldehydes with extremely high stereoselectivities, starting from acetaldehyde and either aromatic or aliphatic $\mathrm{N}$ - 
Boc imines (Scheme 18). The method was extended to crossMannich reactions, furnishing $\beta, \beta^{\prime}$-diamino aldehydes containing three adjacent stereogenic centers.

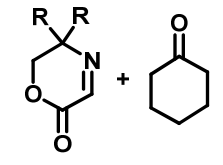

$\mathrm{R}=\mathrm{Me}$ or $\mathrm{Ph}$

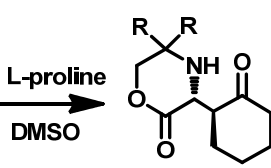

up to $99 \%$ ee up to $90 \%$ yield up to $>20: 1 \mathrm{dr}$
Scheme 17

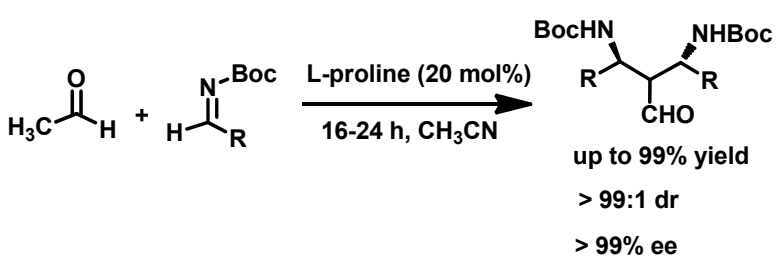

Scheme 18

In 2010, Zhao et al. [28] reported an enantioselective catalytic route to carbamate- and benzoate-protected $\beta$-amino aldehydes and $\beta$-amino acids (Scheme 19). The one-pot organocatalytic reactions between $\alpha$-amido sulfones and unmodified aldehydes proceeded with high chemo- and enantioselectivities to furnish $\beta$-amino aldehydes in high yields with up to $95: 5 \mathrm{dr}$ and up to $99 \%$ ee. 2-Aryl-3H-indol-3-ones reacted with aldehydes or ketones in the presence of L-proline as a catalyst to give the corresponding aza-quaternary carbon addition product with moderate to excellent regioselectivity and enantioselectivity [29]. The system was applied to the reaction of 2-(2-bromo-phenyl)-3H-indol-3-one and acetaldehyde to give 2-[2-(2-bromophenyl)-3-oxoindolin-2-yl] acetaldehyde, which was a precursor for the synthesis of some alkaloids such as hinckdentine A (Scheme 20).

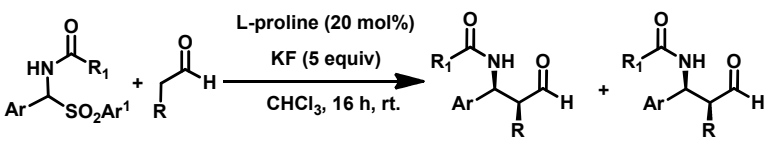

Scheme 19

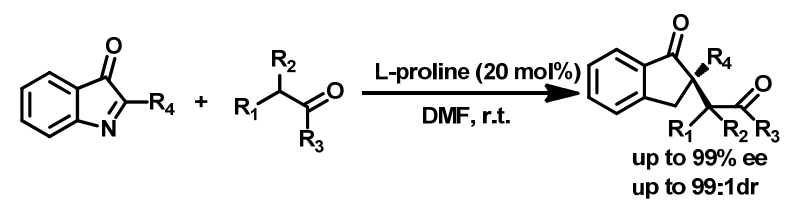

Scheme 20

Sebesta et al. [30] showed L-proline-derived sulfonamides (11) was effective catalysts in the Mannich reaction of cyclohexanone with N-PMP-protected $\alpha$-imino ethylglyoxylate with practical advantages in comparison with L-proline in different solvents and ionic liquids (Scheme 21). A broader range of ionic liquids seems to be necessary to gain deeper insight into the reactivity of these catalysts in the Mannich reaction. Recently, Lu et al. [31] found a highly enantioselective direct Mannich protocol employing fluoroacetone, $p$-anisidine, and aldehydes catalyzed by 4-siloxyproline (12), the approach allowed efficient access for pharmaceutically important fluorinated $\beta$-amino ketones (Scheme 22).

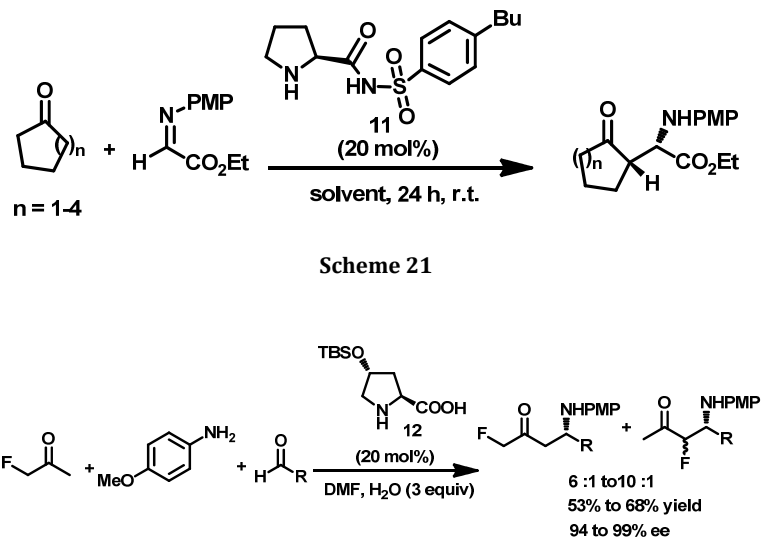

Scheme 22

\subsubsection{Pyrrolidine derivatives}

In 2008, Melchiorre et al. [32] showed the pyrrolidine derivative $\alpha, \alpha$-diarylprolinol trimethylsilyl ether (13) catalyzed anti-selective Mannich reaction of aldehydes with $\mathrm{N}$-Cbz- and $\mathrm{N}$-Boc-protected imines generated in situ from stable amido sulfones (Scheme 23). Besides the high level of efficiency and stereocontrol achieved, this approach introduces important synthetic advantages by avoiding the requirement to preform the $N$-carbamoyl imines. The potential extension of this method to the extremely challenging aliphatic imines would further improve the utility of the aminocatalytic Mannich reaction. The following year, Fustero et al. [33] reported the asymmetric Mannich reaction between fluoroalkyl aldimines and aldehydes catalyzed by $\alpha, \alpha$-diarylprolinol trimethylsilyl ether (13 or 14) (Scheme 24). The corresponding Mannich adducts were reduced in situ to afford anti- $\beta$-alkyl- $\gamma$-fluoroalkyl- $\gamma$-amino alcohols in moderate yields and with very high diastereo- and enantioselectivities. Hayashi et al. [34] also reported an asymmetric Mannich reaction of imines derived from aliphatic and aromatic aldehydes catalyzed by diarylprolinol silyl ether 13 (Scheme 25).

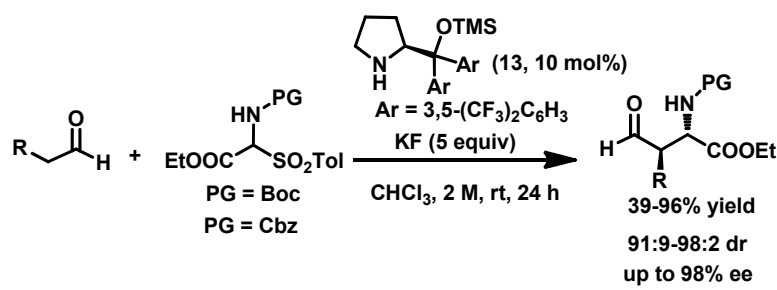

Scheme 23

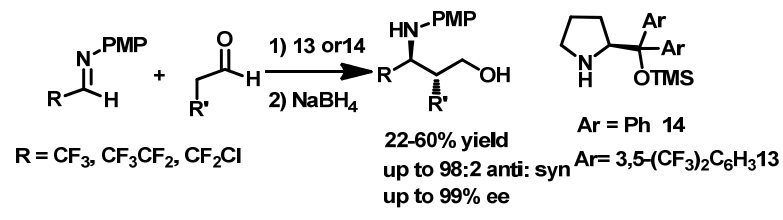

Scheme 24

In 2008, Blanchet [35] reported the direct and threecomponent Mannich reaction using 3-trifluoromethanesulfonamido-pyrrolidine (15) as catalyst which achieved high yields and selectivities for various substrates ranging from linear and branched aldehydes to ketones (Scheme 26). The research disclosed that the acidity of the trifluoromethylsulfonamide group was critical to achieve high 
stereoselectivity, and C-2 symmetry of catalyst was not a key structural feature for a high stereoselectivity. The similar work associatied to the enantioselective anti-selective Mannich-type reactions of aldehydes and ketones with imines catalyzed by 3pyrrolidinecarboxylic acid and related pyrrolidine derivatives was reported by Tanaka in 2008 [36].

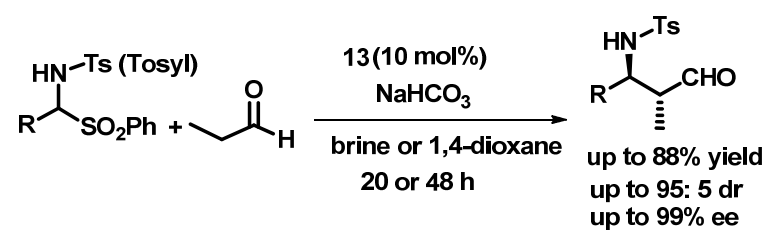

Scheme 25

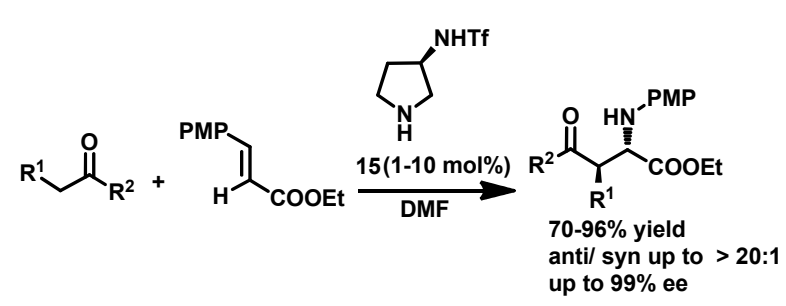

Scheme 26

Hayashi et al. [37] developed an organocatalyst mediated, asymmetric Mannich reaction in the presence of water without using organic solvents (Scheme 27). Reactive siloxytetrazole hybrid catalyst (16) had been developed for the reaction of dimethoxyacetaldehyde, while the Na salt of siloxyproline was an effective catalyst of $\alpha$-imino glyoxylate.

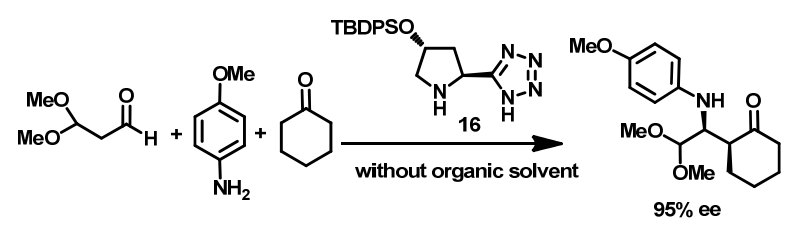

Scheme 27

\subsubsection{Cinchona alkaloids}

Schaus et al. [38] were first to describe the highly enantioselective cinchona alkaloid-catalyzed Mannich reaction of dicarbonyl compounds with $\alpha$-amido sulfones as acyl imine precursors (Scheme 28). The reaction requires $10 \mathrm{~mol} \%$ of the cinchona alkaloid catalyst (17), which served as a general base to generate acyl imines in situ, and aqueous $\mathrm{Na}_{2} \mathrm{CO}_{3}$ to maintain the concentration of free alkaloid catalyst. The reaction products were obtained in good yields and high enantioselectivities, and in diastereoselectivities that range from 1:1 to $>95: 5$.

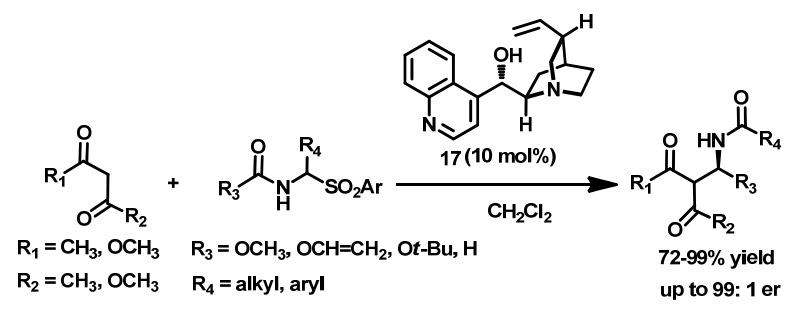

Recently, Wang et al. [39] showed that the cinchona alkaloid catalyst (18) system could perform efficiently the azaMannich addition of 2-(ethylthio)-thiazolones and $N$-tosyl aldimines (Scheme 29). A series of masked chiral 2-(ethylthio)thiazolone derivatives have been synthesized with high levels of diastereo- (up to > 98:2) and enantioselectivities (up to $>99 \%$ ) for the first time. Several new derivatives have been found to show potential anticancer activities.

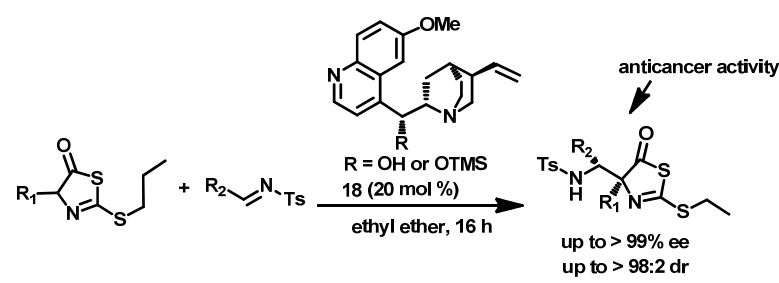

Scheme 29

Shibata and Toru [40] described the first catalytic enantioselective fluorobisphenylsulfonyl methylation of in situ generated imines from $\alpha$-amido sulfones under the combination of Mannich type conditions with $\alpha$ fluorobisphenyl-sulfonylmethylated (FBSM) chemistry (Scheme 30). The FBSM amines were converted to $\alpha$ monofluoromethyl amines by reductive desulfonylation.

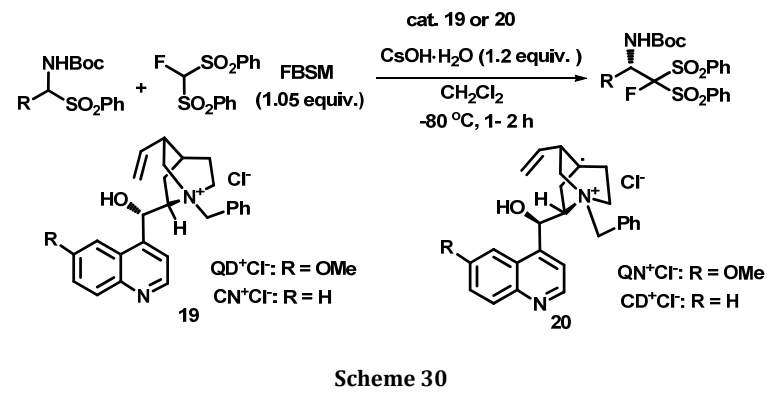

\subsubsection{Other chiral amines}

Maruoka et al. [41] developed a direct asymmetric Mannich reaction using a novel axially chiral amino sulfonamide (21) that was highly anti- and enantioselective (Scheme 31). For instance, in the presence of a catalytic amount of 21, the reactions between aldehydes and $\alpha$-imino esters proceeded smoothly to give anti Mannich products with a significantly higher anti/syn ratio as well as higher enantioselectivity than previously possible. The axially chiral amino sulfonamide $\mathbf{2 1}$ had also been successfully applied to asymmetric direct crossaldol reaction between two different aldehydes. The same year, they also reported that stereoselective direct asymmetric Mannich reaction between acetaldehyde and $N$-Boc-protected imines, as well as an anti-selective direct asymmetric Mannich reaction of $\mathrm{N}$-Boc-protected imines by using the less nucleophilic chiral amino sulfonamide $\mathbf{2 1}$ to suppress the undesired side reactions [42].

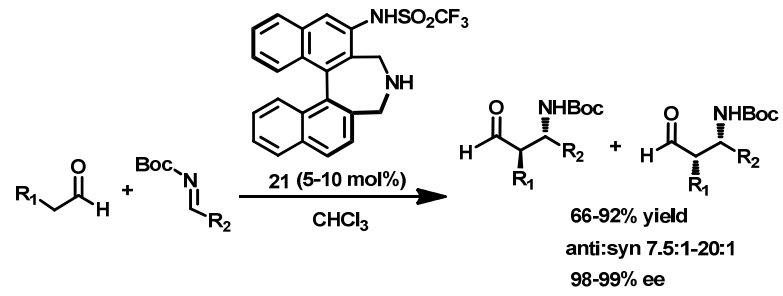

Scheme 31 
In 2011, a highly efficient bisguanidine organocatalyst (22) for the Mannich-type reaction of an isothiocyanato imide with $\mathrm{N}$-Ts-protected imines was developed by Feng (Scheme 32) [43]. Significant progress had been made with an extremely broad substrate scope, giving optically active $\alpha, \beta$-diamino acid derivatives in excellent yields with high diastereoselectivities (up to $>95: 5$ d.r.) and excellent enantioselectivities (up to 99\% ee) under mild conditions. Tan et al. [44] reported the enantioand diastereoselective correponding guanidine-catalyzed Mannich reaction with $\alpha$-fluoro- $\beta$-keto acyloxazolidinone as the fluorocarbon nucleophile. Fluoro- $\beta$-amino acid derivatives with chiral fluorinated carbon were obtained through selective deacylation or decarboxylation reactions.

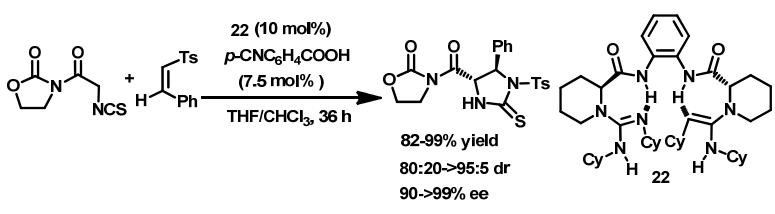

Scheme 32

\subsection{Chiral bifunctional thiourea}

In 2008, a novel bifunctional chiral thiourea organocatalyst (23) bearing a glycosyl scaffold and a tertiary amino group starting from readily available alpha-D-glucose was synthesized by Zhou (Scheme 33) [45]. This thiourea was proven to be an effective organocatalyst for the asymmetric aza-Henry reaction between $N$-Boc imines and nitromethane. The corresponding adducts were obtained in good to excellent yields with excellent enantioselectivities (up to $99.8 \%$ ee). In addition, the reaction of nitroethane also proceeded smoothly with excellent enantioselectivity, albeit with low to good diastereoselectivities.

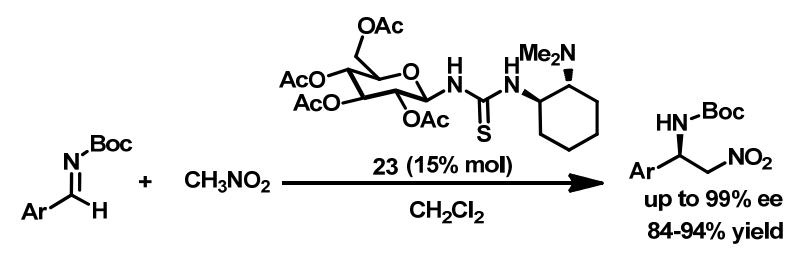

Scheme 33

Chen et al. [46] investigated the asymmetric Mannich reaction of 3-substituted oxindoles and $\mathrm{N}$-Boc imines employing bifunctional thiourea-tertiary amine organocatalysts (24) based on DPEN scaffold (Scheme 34). The novel transformations exhibited high diastereoselectivities, and the Mannich adducts bearing adjacent quaternary and tertiary chiral centers were generally obtained in good to excellent enantioselectivity (up to $95 \%$ ee).

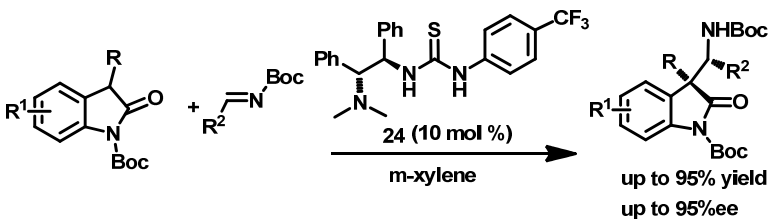

Scheme 34

Wang et al. [47] developed the highly anti-selective (93:799:1) and excellent enantioselective $(96-99 \%$ ee) nitroMannich reactions catalyzed by chiral bifunctional thiourea catalyst (25) bearing multiple hydrogen-bonding donors that performed well over a broad scope of substrates (Scheme 35). This methodology was a nice complement the highly syn- selective version using a herterobimetallic $\mathrm{Cu}$-Sm-Shiff base complex.

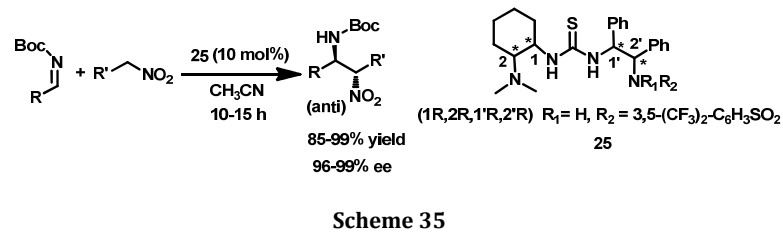

Huang et al. [48] introduced a novel tryptophan based bifunctional thiourea catalyst (26) that was remarkably effective in promoting the asymmetric Mannich reaction of $\alpha$ fluoro- $\beta$-ketoesters (Scheme 36). The resulting compounds with fluorinated quaternary and tertiary stereocenters could be converted readily into $\alpha$-fluoro- $\beta$-amino acids and $\alpha$-fluoro- $\beta$ lactams. Preliminary computational studies suggested that the indole moiety of the catalyst played a crucial role in substrate binding. They discovered that tertiary amine-thiourea bifunctional catalysts could be derived readily from natural amino acids, a strategy which may eventually lead to the discovery of various novel multifunctional organic catalysts.

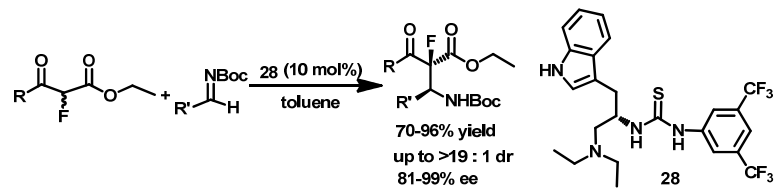

Scheme 36

In 2010, Coltart et al. [49] developed the organocatalytic Mannich reaction based on proximity-assisted intracomplex soft enolization of thioesters using simple derivatives of known cinchona alkaloid-based catalysts (27) (Scheme 37). This approach to enolization was based on the cooperative action of a carbonyl activating hydrogen bonding (thio)urea moiety and an amine base contained within a single catalytic entity to facilitate intracomplex deprotonation. Significantly, this allowed thioesters over a range of acidity to react efficiently, thereby opening the door to the development of a general mode of enolization-based organocatalysis of monocarboxylic acid derivatives.

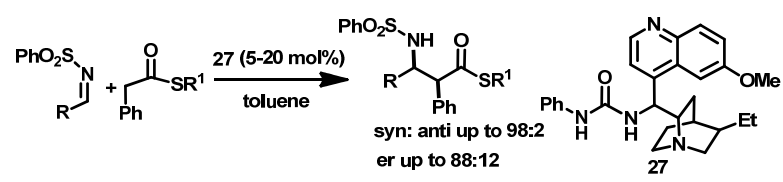

Scheme 37

Lee et al. [50] described the catalytic enantioselective Mannich reaction promoted by chiral bifunctional organocatalysts (28) (Scheme 38). The treatment of diethyl fluoromalonate with $\mathrm{N}$-Boc-aldimines under mild reaction conditions afforded the corresponding $\beta$-amino- $\beta$ fluoromalonates with excellent enantioselectivity (93-97\% ee).

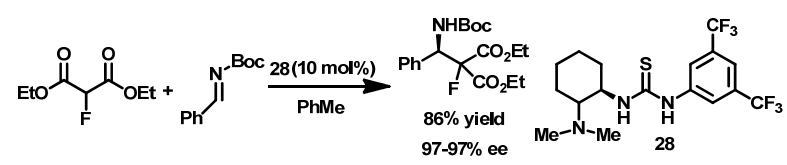

Scheme 38

In 2010, Enders et al. [51] developed an efficient domino Mannich/aza-Michael reaction between carbamate-protected aryl aldimines and $\gamma$-malonate-substituted $\alpha, \beta$-unsaturated 
methyl esters promoted by a bifunctional thiourea catalyst (2932) (Scheme 39). The method furnishes 2,5-cis-configured polysubstituted pyrrolidines in good to excellent yields (7699\%), enantioselectivities (75-94\%) and excellent diastereoselectivities (de $>95 \%$ ).

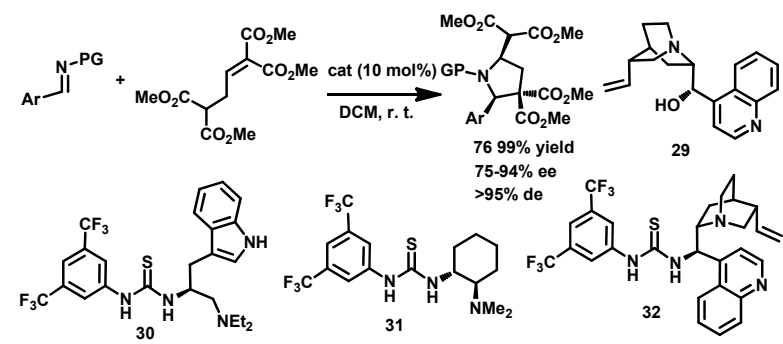

Scheme 39

In 2011, Chuan et al. [52] identified an efficient catalytic system for the direct anti-Mannich reaction of simple aldehydes with preformed $N$-Boc and $N$-Cbz imines (Scheme 40). Only 5 mol\% catalyst (33) loading was needed to give the corresponding products in excellent yields (up to 95\%), diastereoselectivities (up to $96: 4 \mathrm{dr}$ ) and enantioselectivities (up to $>99 \%$ ee).

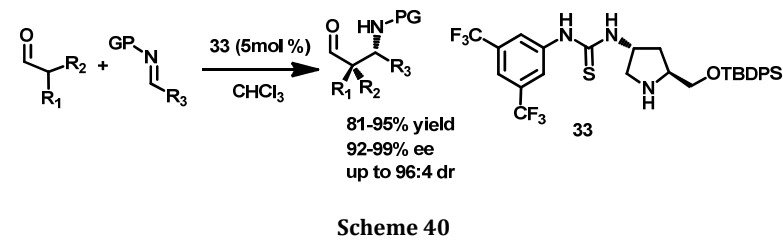

\subsection{Chiral Brønsted acids}

Schneider and co-workers [53] reported that vinylketene silyl N,O-acetals readily participate in Brønsted acid-catalyzed (34) vinylogous Mukaiyama-Mannich reactions with aromatic and heteroaromatic aldimines and furnished $\delta$-amino- $\alpha, \beta$ unsaturated amides in good yields and enantioselectivities (Scheme 41). Direct three-component vinylogous Mannich reactions delivered the products with almost identical yield and enantioselectivity, thus avoiding the synthesis of the imines in a separate step. In 2010, Magnus and Lin [54] developed the enantioselective domino Mannich-ketalization reaction of $o$-hydroxy benzaldimines with electron-rich alkenes catalysed by Brønsted acid (35) (Scheme 42). The reaction sequence provided an easy and direct access to optically pure 4-aminobenzopyrans with excellent enantiomeric ratios (up to e.r. 98:2).

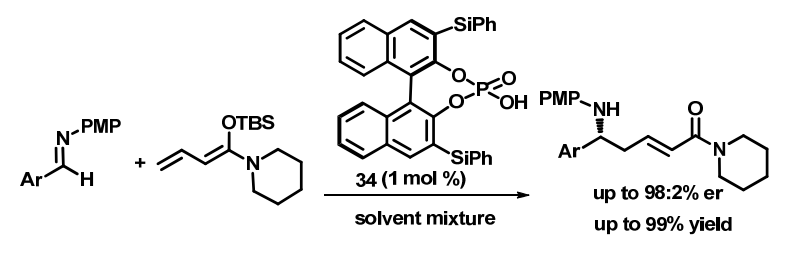

Scheme 41

\section{Other chiral organocatalytic systems}

Hajra et al. [55] found that imidazole-based zwitterionictype molten salts (36) were efficient catalysts for the azaHenry reaction, generating high selectivity in excellent yields (Scheme 43). Most significantly, the syn- $\beta$-nitroamine was obtained predominantly under the present reaction conditions.

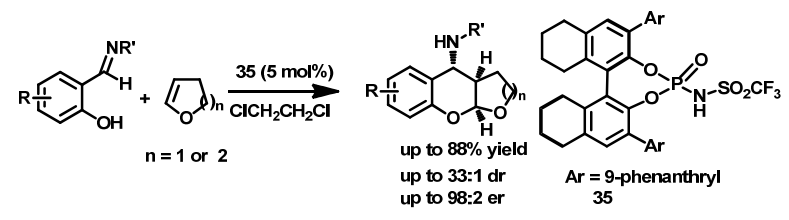

Scheme 42

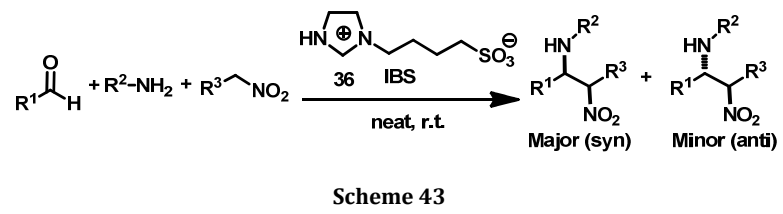

In 2010, Wang et al. [56] reported the employment of CIL [EMIm][Pro] (37) as a catalyst for the one-pot threecomponent asymmetric Mannich reaction with excellent chemo-, regio-, and enantioselectivities either under mild conditions or at a low temperature (Scheme 44). The desired products were isolated in up to $99 \%$ yield and with up to $>99$ $\mathrm{dr}$ and $>99 \%$ ee. Additionally, this catalyst is readily prepared from rather inexpensive starting materials and the reactions could be conducted in wet solvent without an inert atmosphere.

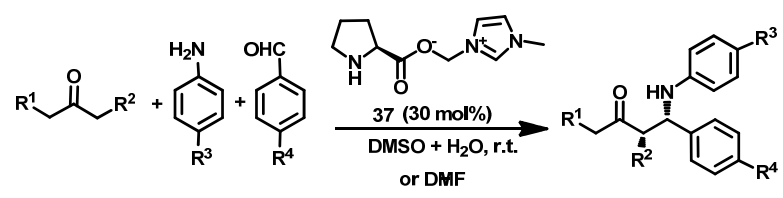

Scheme 44

Different malonates and $\beta$-ketoesters could react with $N$ tert-butoxycarbonyl- $(N$-Boc) and $N$-benzyloxycarbonyl- $(N$-Cbz) protected $\alpha$-amido sulfones in an organocatalytic asymmetric Mannich-type reaction (Scheme 45) [57]. The reaction made use of a simple and easily obtained phase-transfer catalyst (38) and proceeded under very mild and user-friendly conditions. The optimised protocol avoided the preparation and the isolation of the relatively unstable $N$-Boc and $N$-Cbz imines that were generated in situ from the bench-stable $\alpha$-amido sulfones.

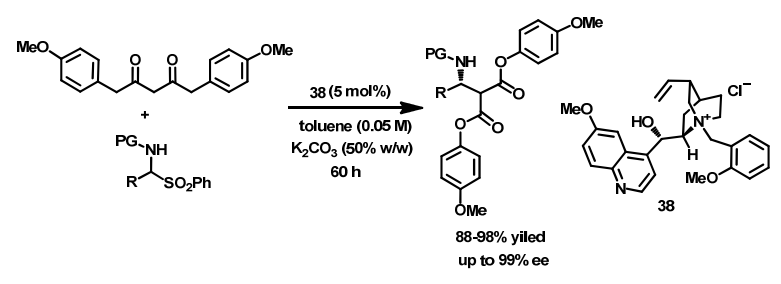

Scheme 45

\section{No chiral catalyst systems}

Some Mannich reactions can achieve highly enantio- and diastereoselective products without chiral catalysts. For example, Dixon et al. [58] developed the stereoselective nitroMannich/lactamization reaction cascade of $\gamma$-nitro esters and cyclic imines for the preparation of multicyclic piperidinone ring containing structures (Scheme 46). The reaction was broad in scope, stereoselective and might be coupled to the asymmetric nitroolefin Michael addition reaction as part of an enantio- and diastereoselective multicomponent process. In 2009, Dixon et al. [59] also reported an efficient threecomponent nitro-Mannich/lactamization cascade of methyl 3nitropropanoate with in situ formed acyclic imines for the 
direct preparation of pyrrolidinone derivatives (Scheme 47). The reaction was easy to perform, broad in scope, and highly diastereoselective and might be extended to cyclic imines allowing the direct formation of polycyclic pyrrolidinone derivatives.

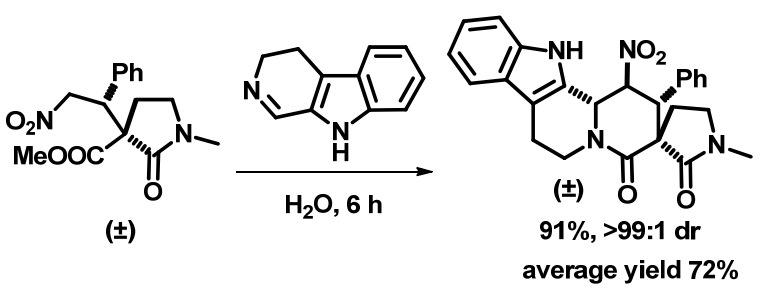

Scheme 46

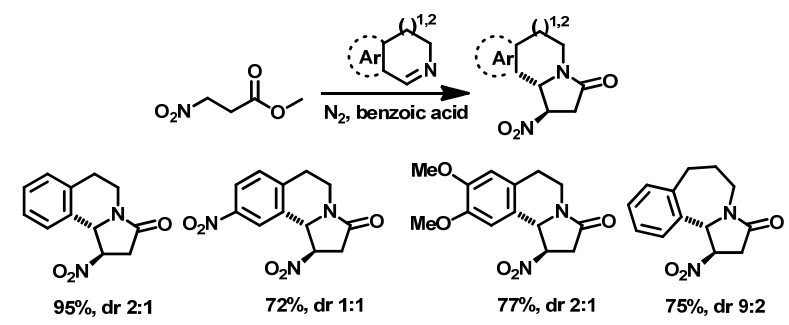

Scheme 47

Giampietro and Wolfe [60] described the highly stereoselective synthesis of enantiomerically enriched $\alpha$-alkyl$\alpha$-hydroxy- $\beta$-amino esters through tandem asymmetric Wittig rearrangement/Mannich reactions (Scheme 48 and 49). This method provided access to a range of syn- and anti-amino alcohol products from simple starting materials, and further illustrated the utility of Wittig rearrangements for stereoselective generation of enolates derived from $\alpha$-alkyl- $\alpha$ hydroxy- $\beta$-amino esters.

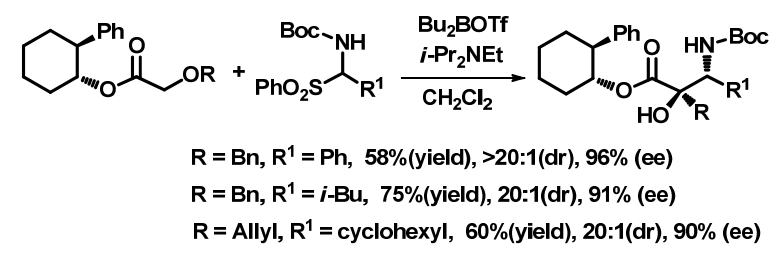

Scheme 48

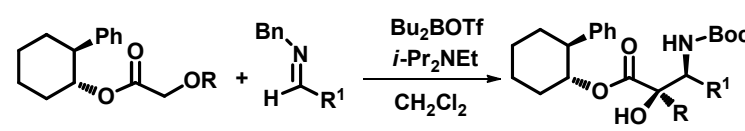

$\mathrm{R}=\mathrm{Bn}, \mathrm{R}^{1}=\mathrm{Ph}, \mathbf{7 1} \%($ yield), >20:1(dr), 96\% (ee)

$R=B n, R^{1}=$ PMP, $85 \%($ yield), 20:1(dr), 90\% (ee)

$R=B n, R^{1}=2$-furyl, $70 \%($ yield), 20:1(dr), $90 \%$ (ee)

$\mathrm{R}=\mathrm{Bn}, \mathrm{R}^{\mathbf{1}}=$ cyclohexyl, 54\%(yield), >20:1(dr), 93\% (ee)

$R=$ Allyl, $R^{1}=P h, 63 \%(y i e l d),>20: 1(d r), 94 \%$ (ee)

$\mathrm{R}=\mathrm{Allyl}, \mathrm{R}^{1}=\mathrm{p}-\mathrm{FC}_{6} \mathrm{H}_{4}, 69 \%$ (yield), $>20: 1(\mathrm{dr}), 94 \%$ (ee)

Scheme 49

In 2011, Liu and Lu [61] developed an efficient, highly diastereoselective method for the preparation of protected cis2-aminocyclopropanols from $N$-tert-butanesulfinyl ketimines and various aryl acylsilanes (Scheme 50). A cascade transformation involving the formation of two C-C bonds and an $\mathrm{O}-\mathrm{Si}$ bond was a key feature of this reaction. They had provided a mechanism rationalizing the observed diastereocontrol for the formation of cis-2-aminocyclopropanol (Scheme 51).

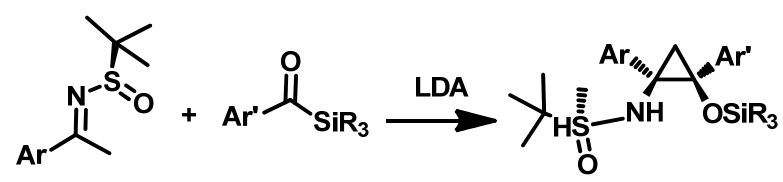

Scheme 50

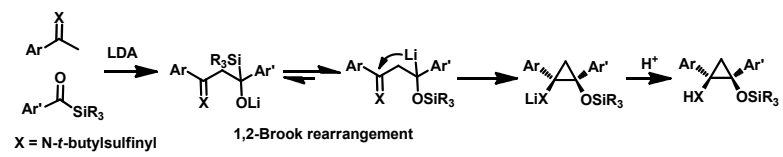

Scheme 51

\section{Conclusions}

This review provides an overview of the recent of the applications of various catalytic systems in asymmetric Mannich reaction. In the past few years, the development of asymmetric Mannich reactions has attracted considerable attention. Such as, the asymmetric Mannich reactions catalysed by metal-based asymmetric organocatalysis have still been developed owing to its highly enantio- and diastereoselectivity and relatively less catalyst loading. At the same time, many novel asymmetric Mannich reactions using other chiral catalytic systems have been reported. In particular, enantioselective organocatalytic processes in Mannich reaction have rapidly been developed with an impressive and steadily increasing number of publications, regarding the applications of this type of reactions. Even though transition-metalcatalysed enantioselective reactions will certainly continue to play a central role in asymmetric Mannich reactions in the future, metal-free catalysts appear to be an emerging trend over the past few years. The application of chiral organocatalysts has permitted the preparation of a number of very valuable chiral products with the exclusion of any trace of hazardous metals and with several advantages from an economical and environmental stand point.

\section{Acknowledgements}

We thank the National Natural Science Foundation of China (20962006) and the Science Foundation of the Guizhou Science and Technology Department (LKM[2011]26) for financial support.

\section{References}

[1]. Cordova, A. Acc. Chem. Res. 2004, 37, 102-112.

[2]. Kobayashi, S.; Ishitani, H. Chem. Rev. 1999, 99, 1069-1094

[3]. Arend, M.; Westermann, B.; Risch, N. Angew. Chem., Int. Ed. 1998, 37, 1044-1070.

[4]. Arrays, R. G.; Carretero, J. C. Chem. Soc. Rev. 2009, 38, 1940-1048.

[5]. Verkade, J. M. M.; van Hemert, L. J. C.; Quaedflieg, P. J. L. M.; Rutjes, F. P. J. T. Chem. Soc. Rev. 2008, 37, 29-41.

[6]. Pellissier, H. Tetrahedron 2007, 63, 9267-9331.

[7]. J. A. Ma, Angew. Chem. Int. Ed. 2003, 42, 4290-4299.

[8]. Liu, M.; Sibi, M. P. Tetrahedron 2002, 58, 7991-8035.

[9]. Müller, R.; Goesmann, H.; Waldmann, H. Angew. Chem. Int. Ed. 1999 38, 184-187.

[10]. Chen, Z. H.; Yakura, K.; Matsunaga, S.; Shibasaki, M. Org. Lett. 2008, 10(15), 3239-3242.

[11]. Shepherd, N. E.; Tanabe, H.; Xu, Y. J.; Matsunaga, S.; Shibasaki, M. J. Am Chem. Soc. 2010, 132, 3666-3667.

[12]. Wang, J.; Shi, T.; Deng, G. H.; Jiang, H. L.; Liu, H. J. Org. Chem. 2008, 73, 8563-8570.

[13]. Kang, Y. K.; Kim, D. Y. Tetrahedron Lett. 2011, 52, 2356-2358.

[14]. Handa, S.; Gnanadesikan, V.; Matsunaga, S.; Shibasaki, M. J. Am. Chem. Soc. 2010, 132, 4925-4934. 
[15]. Zhang, Q.; Hui, Y. H.; Zhou, X.; Lin, L. L.; Liu, X. H.; Feng, X. M. Adv. Synth. Cat. 2010, 352, 976-980.

[16]. Zhou, L.; Lin, L. L.; Ji, J.; Xie, M. S.; Liu, X. H.; Feng, X. M. Org. Lett. 2011, 13, 3056-3059.

[17]. Zhao, Q. -Y.; Yuan, Z. -L.; Shi, M. Tetrahedron-Asymmetr. 2010, 21, $943-$ 951.

[18]. Zhao, Q. -Y.; Shi, M. Tetrahedron 2011, 67, 3724-3732.

[19]. Curti, C.; Battistini, L.; Ranieri, B.; Pelosi, G.; Rassu, G.; Casiraghi, G.; Zanardi, F. J. Org. Chem. 2011, 76, 2248-2252.

[20]. Poisson, T.; Tsubogo, T.; Yamashita, Y.; Kobayashi, S. J. Org. Chem. 2010, 75, 963-965.

[21]. Liang, G.; Tong, M. -C.; Tao, H. Y.; Wang, C. -J. Adv. Synth. Cat. 2010 352, 1851-1855.

[22]. Hernandez-Toribio, J.; Arrayas, R. G.; Carretero, J. C. Chem. Eur. J. 2010, 16, 1153-1157.

[23]. List, B. J. Am. Chem. Soc. 2000, 122, 9336-9337.

[24]. List, B.; Pojarliev, P.; Biller, W. T.; Martin, H. J. J. Am. Chem. Soc. 2002, 124, 827-833.

[25]. Chandler, C.; Galzerano, P.; Michrowska, A.; List, B. Angew. Chem. Int. Ed. 2009, 48, 1978-1980.

[26]. Han, R. -G.; Wang, Y.; Li, Y. -Y.; Xu P. F. Adv. Synth. Cat. 2008, 350, 1474-1478.

[27]. Hahn, B. T.; Frohlich, R.; Harms, K.; Glorius, F. Angew. Chem. Int. Ed. 2008, 47, 9985-9988.

[28]. Deiana, L.; Zhao, G. -L.; Dziedzic, P.; Rios, R.; Vesely, J.; Ekstr, J.; Cordova, A. Tetrahedron Lett. 2010, 51, 234-237.

[29]. Li, L. Q.; Han, M. Y.; Xiao, M. X.; Xie, Z. X. Synlett 2011, 1727-1730.

[30]. Veverkova, E.; Strasserova, J.; Sebesta, R.; Toma, S. Tetrahedron: Asymmetry 2010, 21, 58-61.

[31]. Lu, M.; Lu, Y. P.; Tan, P. K. A.; Lau, Q. Y.; Zhong, G. F. Synlett 2011, 477480.

[32]. Gianelli, C.; Sambri, L.; Carlone, A.; Bartoli, G.; Melchiorre, P. Angew. Chem. Int. Ed. 2008, 47, 8700-8702.

[33]. Fustero, S.; Mojarrad, F.; Carrion, M. D. P.; Sanz-Cervera, J. F.; Acena, J. L. Eur. J. Org. Chem. 2009, 5208-5214.

[34]. Urushima, T.; Ishikawa, H.; Hayashi, Y. Chem. Eur. J. 2011, 17, 82738276.

[35]. Pouliquen, M.; Blanchet, J.; Lasne, M. -C.; Rouden, J. Org. Lett. 2008, 10 , 1029-1032.

[36]. Zhang, H. L.; Mitsumori, S.; Utsumi, N.; Imai, M.; Garcia-Delgado, N.; Mifsud, M.; Albertshofer, K.; Cheong, P. H. -Y.; Houk, K. N.; Tanaka, F. J.; Barbas, C. F. J. Am. Chem. Soc. 2008, 130, 875-886.

[37]. Hayashi, Y.; Urushima, T.; Aratake, S.; Okano, T.; Obi, K. Org. Lett. 2008, 10, 21-24

[38]. Lou, S.; Dai, P.; Schaus, S. E. J. Org. Chem. 2007, 72, 9998-10008.

[39]. Liu, X. D.; Deng, L. J.; Song, H. J.; Jia, H. Z.; Wang, R. Org. Lett. 2011, 13 1494-1497.

[40]. Mizuta, S.; Shibata, N.; Goto, Y.; Furukawa, T.; Nakamura, S.; Toru, T. J. Am. Chem. Soc. 2007, 129, 6394-6395.

[41]. Kano, T.; Yamaguchi, Y.; Maruoka, K. Chem. Eur. J. 2009, 15, 66786687.

[42]. Kano, T.; Yamaguchi, Y.; Maruoka, K. Angew. Chem. Int. Ed. 2009, 48, 1838-1840.

[43]. Chen, X. H.; Dong, S. X.; Qiao, Z.; Zhu, Y.; Xie, M. S.; Lin, L. L.; Liu, X. H.; Feng, X. M. Chem. Eur. J. 2011, 17, 2583-2586.

[44]. Pan, Y. H.; Zhao, Y. J.; Ma, T.; Yang, Y. Y.; Liu, H. J.; Jiang, Z. Y.; Tan, C. -H. Chem. Eur. J. 2010, 16, 779-782.

[45]. Wang, C. G.; Zhou, Z. H.; Tang, C. C. Org. Lett. 2008, 10, 1707-1710.

[46]. Tian, X.; Jiang, K.; Peng, J.; Du, W.; Chen, Y. -C. Org. Lett. 2008, 10, 3583-3586.

[47]. Wang, C. -J.; Dong, X. -Q.; Zhang, Z. -H.; Xue, Z. -Y. and Teng, H. -L. J. Am. Chem. Soc. 2008, 130, 8606-8607.

[48]. Han, X.; Kwiatkowski, J.; Xue, F.; Huang, K. -W.; Lu, Y. X. Angew. Chem. Int. Ed. 2009, 48, 7604-7607.

[49]. Kohler, M. C.; Yost, J. M.; Garnsey, M. R.; Coltart, D. M. Org. Lett. 2010, 12, 3376-3379.

[50]. Hee. L. J.; Kim, D. Y. Synthesis 2010, 1860-1864.

[51]. Enders, D.; Goddertz, D. P.; Beceñe, C.; Raabe, G. Adv. Synth. Cat. 2010, 352, 2863-2868.

[52]. Chuan, Y. -M.; Chen, G. -H.; Gao, J. -Z.; Zhang, H.; Peng, Y. -G. Chem. Commun. 2011, 47, 3260-3262.

[53]. Giera, D. S.; Sickert, M.; Schneider, C. Org. Lett. 2008, 10, 4259-4262.

[54]. Rueping, M.; Lin, M. -Y. Chem. Eur. J. 2010, 16, 4169-4172.

[55]. Kundu, D.; Debnath, R. K.; Majee, A.; Hajra, A. Tetrahedron Lett. 2009, 50, 6998-7000.

[56]. Zheng, X.; Qian, Y. -B.; Wang, Y. M. Eur. J. Org. Chem. 2010, 515-522.

[57]. Marianacci, O.; Micheletti, G.; Bernardi, L.; Fini, F.; Fochi, M.; Pettersen, D.; Sgarzani, V.; Ricci, A. Chem. Eur. J. 2007, 13, 8338-8351.

[58]. Jakubec, P.; Helliwell, M.; Dixon, D. J. Org. Lett. 2008, 10, 4267-4270.

[59]. Sophie M. -C.; Pelletier, P.; Ray, C.; Dixon, D. J. Org. Lett. 2009, 11, $4512-4515$

[60]. Giampietro, N. C.; Wolfe, J. P. Angew. Chem. Int. Ed. 2010, 49, $2922-$ 2924.

[61]. Liu B.; Lu, C. -D. J. Org. Chem. 2011, 76, 4205-4209. 